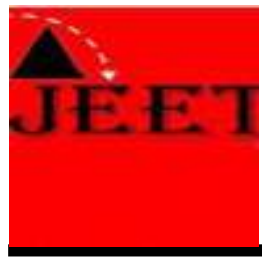

\title{
Optimizing LMS CANVAS for Interactive Online Learning Perceived by the Students
}

\author{
Santiana \\ Universitas Siliwangi \\ santiana@unsil.ac.id \\ Dea Silvani \\ Universitas Siliwangi \\ dea.silvani@unsil.ac.id \\ Ruslan \\ Universitas Siliwangi \\ ruslan@unsil.ac.id
}

Corresponding email: santiana@unsil.ac.id

\begin{abstract}
Recently, technology has been an integral part of education. Teachers must use technology into their teaching practices in order to adapt to society's digital revolution. One of the strategies that can be implemented by the teachers is utilizing Canvas as one of Learning Management Systems (henceforth LMS) in their course. This study aims to investigate the students' perception towards the use of Canvas to promote interactive online learning. Implementing case study as the research design, this study involved 77 students as the participants, and used both questionnaire and semi-structured interview to collect the data. In this study, the quantitative data were analyzed using descriptive statistics, while the qualitative data were analyzed using thematic analysis. The findings of this study revealed that students accessed Canvas ranging for less than 1 hour to more than 2 hours in a week. They accessed it mostly to join some learning activities designed by the teacher, including reading the learning modules, joining online discussion, and doing the assignments given by the teachers. They also believe that during the online learning, Canvas is an easy-to-use LMS, and it provides a lot of features that help them learning. Besides, they also agree that Canvas is effective to provide them the opportunity have an interactive learning experience. In addition, they also perceived that using Canvas motivated them, and make the learning process more interesting. Therefore, teachers can optimize various features provided by Canvas to make the teaching and learning process in online setting become more interactive, interesting, and effective.
\end{abstract}

Keywords: Canvas, Learning Management System; online learning; students' perception 


\section{Introduction}

As a result of digital revolution in the society, the rapid development of technological advancement has brought about some changes in education. It is an essential part of the teachers' profession, and they can use it to help students learn. In this regard, Nomass (2013) believes that nowadays, using technology in learning has become a real necessity. In addition, in order to improve the quality of education, the educational practitioners are required to meet the global requirement by keep adapting with technology development. A variety of technology tools are now available to assist teachers in improving their teaching techniques. However, the teachers should be able to carefully choose the appropriate technology, and optimizing its use so that it can support the effectiveness of teaching and learning process. They have to be able to follow the modern technical ways in order to create effective learning and teaching of the second language (Nomass, 2013). For those reasons, besides they should be confident in using the technology, teachers also need to have adequate knowledge related to the course content, pedagogical aspects, and the technology to integrate it effectively in the classroom practice (Ertmer \&OttenbreitLeftwich, 2010).

Considering the current situation, the teachers are required to be familiar with and to be able to conduct online learning as one of the solutions to cope with the Covid-19 pandemic. Utilizing a Learning Management System (LMS) is considered to be a prevailing strategy used by the teachers in their teaching practices (Basal, 2016). LMS is a broad term that describes various systems that provide students, teachers, as well as manager the online educational services (Aldiab, Chowdhury, Kootsookos, Alam, \& Allhibi, 2019), which basically functions to supports, organize, arrange, and manage the training course (Khoa, Ha, Nguyen \& Bich, 2020). Moreover, Fathema, Shannon \& Roos (2015) also claim that LMS provides improved and faster communications virtually among students and teachers as well as offers pace and effectiveness in educational process for it offers several features to support the instruction. Moreover, by using LMS, the process of teaching and learning no longer depends on offline class (face-to-face), but it also can be done outside of the classroom (Al Khoeri, Nuraini, Ramdani, \& Agum 2021). In other words, teachers can utilize LMS for the more effective online learning by optimizing various features provided by the LMS in designing and conducting the instruction, which 
enables the opportunity to communicate virtually with the students during the learning process. In addition, it can be easily accessed anywhere and anytime. Therefore, it is expected that by using LMS, there will be more intense interactions between students and teacher in online learning setting.

One of the LMS that can be utilized by the teacher is Canvas. Canvas is a learning management system, or LMS, which is an online learning platform that allows teachers and students to exchange information and communicate with one another during a course. In other words, Canvas is one of the Learning Management Systems (LMSs) used to manage classroom activity (AI Khoeri, Nuraini, Ramdani, \& Agum 2021). Canvas offers various beneficial features that can be utilized by the teachers optimally to improve the effectiveness of teaching and learning process. It enables the opportunity for the teachers to conveniently access the discussion, course calendars, lecturing videos, grade, assignments, messaging analytics, reports, group, peer review assignment, and other educational applications (Pujasari \& Ruslan, 2021). However, when deciding to use Canvas in their teaching practices, the teachers are required to proficiently maximize the use of Canvas, by having adequate knowledge and capability to operate it, and thus it can promote the more interactive, and effective instruction. It is because the selection of the appropriate media in learning can generate a good output regarding to the current conditions and needs (Jusuf, Ibrahim, Suparman, 2021).

Nonetheless, ensure the success of teaching and learning process, it is important for the teachers to also consider students' perception towards the innovation implemented by the teacher, in this case is using Canvas for online learning. Specifically in this study, perception refers to students' primary form of cognitive contact with the environment surround them (Efron, 1969). In attempt to reveal students' perception towards the use of Canvas to support the interactive online learning, this study tries to apply Technology Acceptance Model (TAM) by Davis (1989). This model posits that when someone is introduced to a new technology, his or her decision to utilize it will be influenced by a number of characteristics, including perceived ease of use (PEOU) and perceived usefulness (PU) (Binyamin \& Smith, 2019), (Davis, 1989). PEOU refers to the degree to which a person believes that using certain technology would be effortless, while perceived usefulness refers to the degree to which a person believes that using a particular system can improve his or her performance (Davis, 1989). 
In fact, perceptions in educational research have been produced by many researchers. For instance, Carbonilla \& Bhati (2016) who tried to investigate students' perception on the use of technology in the classroom especially at higher education institutions in Philippines. They observed the students' perceptions after giving the students a treatment to use technology in the classroom. The result showed that most students have negative consequences using mobile internet. Another study by Ekinci and Ekinci (2017), investigated about students' perceptions of using a mobile application for English language learning. The result showed that mobile applications might be enlightening for EFL learners by providing advantages and disadvantages of using them. Furthermore, Fatimah \& Santiana (2017) examined students-teachers' perceptions of technology use in the classroom in relation to teaching in the $21^{\text {st }}$ century. They found that using technology as teaching media can provide students a better learning experience.

However, there are still very few studies that examine the students' perceptions regarding the use of Canvas to support interactive online learning activities. Therefore, in the context of this present research, the researcher endeavor in investigating the students' perception on optimizing LMS canvas for interactive learning.

\section{Research Methodology}

The research design for this present research was a case study. The case study discussed a real context phenomenon where the boundaries between the phenomenon and the scope are not pretty obvious; and where descriptive studies are used (Yin, 2003). It allows researchers to closely analyze the data within a particular context, which is to explore students' perceptions of utilizing LMS Canvas to optimize interactive learning. This research was conducted in the English Education department at one of the universities in Tasikmalaya, West Java. The participants of the research are 77 students who are enrolled in the Technology Enhanced Language Learning (TELL) Course 2021. The non-probability sampling voluntary sampling technique was used in this present research. They are students in the English Department in their sixth semester, with an age range ranked between 20-21 years old. The researcher used questionnaires and semi-structured interviews (SSIs) with the participants to collect data, and ask some questions about their perceptions of using LMS Canvas for interactive learning. According to Adams 
(2015), semi-structured interviews are appropriate for various useful tasks, especially when more than a few open-ended questions need follow-up questions. As a result, this type of interview is suitable for the research design (descriptive case study), which is intended to present accurate information about how the participants feel and think. The data was analyzed to determine the optimizing LMS Canvas for interactive learning as perceived by the students who enrolled in the Technology Enhanced Language Learning Class. Furthermore, data from the questionnaires were analyzed using a Likert scale and then statistically calculated. Moreover, data from interviews were analyzed by using Braun and Clarke's (2006) thematic analysis, which involves the following steps: (1) familiarizing with the data, (2) generating initial codes, (3) searching for themes, (4) reviewing themes, (5) defining and naming themes, and (6) producing the report.

\section{Findings and Discussion}

\section{Findings}

This study aims is to investigate students' perception of using LMS Canvas for optimizing interactive online learning. After analyzing the result of questionnaire and semi-structured interview, the researchers discovered that the students perceived Canvas as an easy-to-use LMS for online learning. In addition, they also think that Canvas is effective to support the interactive communication between teacher and students, also between students with their fellow friends during the online learning. There are several highlighted points from the findings of this study. They are the actual use of Canvas by the students, the ease of using Canvas for online learning, the effectiveness of Canvas to promote interactive online learning, and students' attitude of using Canvas for online learning.

\section{The Actual use of Canvas by the Students}

In general, the average time that students spent to access Canvas ranging from less than an hour to more than 2 hours as presented in Table 1 below:

Table 1: Average Time of using Canvas

\begin{tabular}{|c|c|c|}
\hline No & Average Time (hour) & Frequency (\%) \\
\hline 1 & $<1$ & 43 \\
\hline 2 & $1-2$ & 34 \\
\hline 3 & $>2$ & 13 \\
\hline
\end{tabular}

They accessed Canvas mostly to read the materials before their class schedule began by accessing the module that had been posted by the 
teacher previously, and also to check the assignments that had been given by the teacher through Canvas. Besides, they also joined the online discussion held by the teacher in Canvas. Through this activity, they can communicate both with the teacher and with the other students to express their opinion, share their ideas, and give their response related to certain topic. Therefore, they could experience the more interactive learning activities through Canvas.

\section{The Ease of Using Canvas for Online Learning}

Furthermore, the students also admitted that Canvas is an easy LMS to use for online learning. Table 2 below presents students' perception related to the ease of using Canvas for Online Learning:

Table 2: The Ease of using Canvas for Online Learning

\begin{tabular}{|c|l|c|c|c|c|}
\hline No & \multicolumn{1}{|c|}{ Questions } & $\begin{array}{c}\text { Strongly } \\
\text { Agree }\end{array}$ & Agree & Disagree & $\begin{array}{c}\text { Strongly } \\
\text { Disagree }\end{array}$ \\
\cline { 3 - 6 } & $\begin{array}{c}\mathbf{( \% )} \\
\mathbf{( \% )}\end{array}$ & $\mathbf{( \% )}$ & $\mathbf{( \% )}$ \\
\hline 1. & $\begin{array}{l}\text { Canvas is easy to use, especially when it } \\
\text { comes to submitting assignments. }\end{array}$ & 48.1 & 44.1 & 6.5 & 1.3 \\
\hline 2 & $\begin{array}{l}\text { Canvas as a mobile learning tool is } \\
\text { tough to utilize. }\end{array}$ & 5.2 & 24.7 & 61 & 9.1 \\
\hline 3 & $\begin{array}{l}\text { Canvas is challenging to use because } \\
\text { to my mobile's poor internet } \\
\text { connection. }\end{array}$ & 7.8 & 33.8 & 49.3 & 9.1 \\
\hline
\end{tabular}

From Table 2, we can infer that most of the students (92.2\%) felt convenient to use Canvas as an LMS in online learning, especially for submitting assignments given by the lecturer. In addition, they disagreed (70.1\%) to consider Canvas as a difficult learning application to use in their mobile phone. This means that they can easily access the Canvas application that can be installed in their mobile phone, and join the learning activities provided by the lecturer in Canvas from anywhere. In addition, $58.4 \%$ students had stable internet connection on their mobile phone, so they can easily access the LMS. However, some students (41.6\%) faced some internet connection problem that interfere their access to Canvas.

In addition, the result of the semi-structured interview also demonstrates the students' admission that Canvas has some beneficial features that are easy to be accessed by them. This can be seen from Excerpt 1 below: 


\section{Excerpt 1}

Canvas modules serve many details information that I need in learning like home module, good student starter kit, course syllabus module, weekly module, and many more. It was a student-friendly learning platform because everything in the canvas modules and the features help me to learn. The features of module and symbols are easy to operate, the layout is very engaging. All information are organized well in each module with the specific title and subtitle which really help me whenever I need that information. It is easy to access and operate too. (S1)

Besides providing various features, Canvas also has an interesting and engaging layout that attracts their attention in online learning. In addition, the teacher also organized the learning modules structurally, so the students found it easy to access any information they need in the LMS. In other words, the course design provided by the teacher in Canvas also help students to join the learning activities more easily.

\section{The Effectiveness of Canvas to Promote Interactive Online Learning}

Besides the ease of use, students also believe that Canvas is an effective LMS to promote interactive online learning. The results of questionnaire proves that students found some beneficial use of Canvas that can make the learning process become more interactive as can be seen from table 3 below:

Table 3: The Effectiveness of Using Canvas for Interactive Online Learning

\begin{tabular}{|c|c|c|c|c|c|}
\hline \multirow[t]{2}{*}{ No } & \multirow[t]{2}{*}{ Questions } & $\begin{array}{c}\text { Strongly } \\
\text { Agree }\end{array}$ & Agree & Disagree & $\begin{array}{l}\text { Strongly } \\
\text { Disagree }\end{array}$ \\
\hline & & (\%) & (\%) & (\%) & (\%) \\
\hline & $\begin{array}{l}\text { My lecturer's reference resources (videos, } \\
\text { power point files, articles) and assignments } \\
\text { placed in Canvas assist me improve my } \\
\text { learning and better understand the } \\
\text { contents/topics of the class. }\end{array}$ & 58.4 & 41.6 & 0,0 & 0,0 \\
\hline & $\begin{array}{l}\text { Canvas activities and discussions can } \\
\text { encourage me to learn more about the } \\
\text { subject. }\end{array}$ & 36.4 & 59.7 & 3.9 & 0,0 \\
\hline & The use of Canvas saves effort and time. & 31.2 & 67.5 & 0,0 & 1.3 \\
\hline & $\begin{array}{l}\text { The use of Canvas helps me practicing my } \\
\text { language skills }\end{array}$ & 32.5 & 62.3 & 5.2 & 0,0 \\
\hline & $\begin{array}{l}\text { Canvas helps me acquiring new English } \\
\text { vocabularies. }\end{array}$ & 35.1 & 62.3 & 2.6 & 0,0 \\
\hline & $\begin{array}{l}\text { The use of Canvas makes my reading } \\
\text { experience more interesting }\end{array}$ & 50.6 & 42.9 & 6.5 & 0,0 \\
\hline & $\begin{array}{l}\text { The use of Canvas increases the effectiveness } \\
\text { of learning }\end{array}$ & 44.1 & 49.4 & 6.5 & 0,0 \\
\hline & $\begin{array}{l}\text { Canvas allows lecturers and students to } \\
\text { interact and communicate more easily. }\end{array}$ & 49.4 & 41.6 & 9 & 0,0 \\
\hline & $\begin{array}{l}\text { Instead of reading my courses on Canvas, } 1 \\
\text { prefer to read them on paper. }\end{array}$ & 10.4 & 35.1 & 50.6 & 3.9 \\
\hline
\end{tabular}


10 The independent session on Canvas helps my material understanding before Zoom Meeting

51.9

46.8

0,0

1.3

Table 3 above presents the students' perception related to the effectiveness of using Canvas for interactive online learning. Based on the result of the questionnaire, the students (93.5\%) believe that Canvas can support the effectiveness of learning, since it can facilitate the communication between students and teacher that make learning process becomes more interactive $(91 \%)$. It is because the online activities provided by the teacher through Canvas including online discussion motivate them to learn more about the topic being discussed (96.1\%). Moreover, the students assume that using Canvas saves their time and efforts (98.7\%), since the materials and the assignments posted by the teacher help them to gain a better understanding and enhance their learning (100\%). In addition, most of them (98.7\%) admit that by accessing Canvas before their course schedule helped them understanding the materials before the Zoom meeting session with their teacher. Canvas also provides the opportunity to practice their language skills (94.8\%), since it can make their reading experience more interesting (93.5\%) and therefore they prefer to read the materials in their course through Canvas (54.9\%). Besides, they $(94.8 \%)$ can also gain some new vocabulary items from the online learning activities provided by the teacher in Canvas.

\section{Students' attitude towards the use of Canvas for interactive online learning}

From table 3, students found that Canvas is an interesting and a motivating LMS to use for online learning. They stated that Canvas improves their learning motivation (96.1\%), since it allowed them to join online discussion. This activity required them to share their ideas or opinion related to the topic being discussed, which motivated them to learn more about the topic. Through this activity, they are encouraged to be more interactive in communicating their ideas during the learning activity. It can be seen from the Excerpt 3 below:

\section{Excerpt 3}

It is interactive and more interesting to learn through Canvas. (S1) 
In addition, students also agreed (93.5\%) that Canvas is an interesting LMS to use, for it provides them the new reading experience. In this course, the teachers often posted a learning module for each topic, and the students were required to have their independent session to read the module before their class began. That is why they (98.7\%) also claimed that by doing so, they are assisted to obtain a better understanding of the materials before the Zoom meeting session with their teacher.

In spite of its supportive role, there are actually several factors that hinder the students from using Canvas in online learning. In Table 2, some students $(58.4 \%)$ experience a poor internet connection in accessing the Canvas from their phone, which requires them to use their PC to access the LMS for the ease of use (see Excerpt 4).

\section{Excerpt 4}

I think, if I open it on my mobile phone, it's not easy to use because sometimes the system gets slower. So, I should open it in my PC (every time) if I want to use it easily. (S2)

Moreover, they $(29.9 \%)$ also face some difficulties in operating the LMS related to its notification system. Sometimes, they missed the notification when the teacher has posted the materials and assignments in Canvas, because the notification button is not displayed clearly in the main menu. Hence, if they do not take a look carefully, sometimes they missed the notifications. It can be seen in Excerpt 5 below:

\section{Excerpt 5}

Sometimes it's confusing when I want to see the notification, I mean the place of the notification button is not placed in the sidebar (same place as account, dashboard, courses, etc. button) so that sometimes I missed the notification. (S3)

However, those technical issue did not hinder their participation in joining the learning activities in Canvas. They still found that in general Canvas provides beneficial use to support the online learning process.

To sum up, even some students experienced some issues to access Canvas, the findings of this study reveal that Canvas is a beneficial LMS to use for online learning. It has some features that are easy to operate and can be accessed easily. It also provides the opportunity for the students to interact with the teacher and with other 
students during the learning activities in this online platform. Furthermore, it can also help them practicing their language skill, and promote their reading comprehension so that they can obtain a better understanding, and as a result, it enhance the effectiveness of the instruction.

\section{Discussion}

This research attempts to examine students' perception towards the use of Canvas for interactive online learning. Using Canvas for online learning can be a valuable strategy to be implemented by the teacher to elevate the effectiveness of teaching and learning process. In this regard, Al-Khoeri, Nuraini, Ramdani \& Agum (2021) believe that LMS is one of the most valuable solutions in the online learning environments for both students and teachers. It is because aside from various features offered by Canvas that can be utilized by the teacher, the findings of this study also reveal that the students positively perceived the use of it in the course that they take. The results of this study highlighted the students' actual use and their attitudes towards the use of Canvas, along with the ease of using, and its effectiveness to promote the interactive online learning seen from the students' perspective.

Canvas offers a wide range of features that are enabled to be explored by the teacher in conducting online instruction. In this present study, students specifically accessed Canvas for several purposes, including reading the module, joining the online discussion, checking and submitting assignments, and so on, within the duration ranging from less than an hour to more than two hours per week. It indicates that Canvas provides various numbers of features that enable the teacher to optimize each of it to support the teaching and learning process such as dashboard, courses, calendar, announcements, syllabus, modules, discussion form, conference, collaboration application feature, and many more. (Al-Khoeri, Nuraini, Ramdani, \& Agum, 2021). In this regard, the teachers should thoroughly choose an appropriate LMS that allows the teachers to provide some learning resources as well as maximize collaborative features such as discussing certain topic, sharing files and forums (Adzharuddin \& Ling, 2013). For that reason, teachers should also consider whether or not the features provided by the chosen LMS can contribute to improve 
the effectiveness of the instructional process. Nonetheless, the findings of this study, accentuate that most of the students agree with the benefits of Canvas for online learning. Fauzi et.al (2020) also believe that Canvas has more superior features compared to other e-learning that is widely used, which makes it become one of the best e-learning in learning management.

Besides numerous features offered by Canvas, the students also assume that Canvas is an easy-to-use LMS that contributes in supporting the teaching and learning process. It is in line an assumption that it is a platform for student success with some easy-to-use LMS features (Al-Khoeri, Nuraini, Ramdani \& Agum's, 2021; Fauzi et al, 2020). In addition, using Canvas is considered to be beneficial, since it offers an easy access to receive the course materials (Pujasari \& Ruslan, 2021). Moreover, the result of a study initiated by Edmunds, Thorpe, \& Conole (2012) confirms that students perceived that by using ICT (in this study present study is Canvas), makes their learning becomes easier. It means that besides Canvas provides various features that can be utilized by the teacher and the students during the online learning, it can also be operated easily by the students. They can access it anywhere and anytime, since they can simply use their mobile phone to open this LMS. Furthermore, the students also think that the layout of Canvas is interesting, which helps them easily find the information they need in this LMS.

Furthermore, Canvas is also perceived as an effective LMS to promote interactive online learning. Al-Khoeri, Nuraini, Ramdani \& Agum (2021) assume that Canvas offers modern learning tools that can support student engagement, instructor innovation, and widespread connection and collaboration. By offering various features for learning activities, Canvas can facilitate teacher and students communication and make the learning process more interactive. It can encourage students to actively participate in the learning activities provided by the teacher through Canvas. In connection with that matter, the need to interact during teaching and learning process can encourage students' intrinsic motivation which can lead them to be competent and autonomous in learning (Fandiño, Muñoz, \& Velandia, 2019). Besides, Andrei (2017) also argues that the new technology should be appropriately used for inviting the students to take part in hands-on activities, cooperation, and collaboration. Furthermore, Canvas provides benefits for teachers and students to share their knowledge (Al-Khoeri, Nuraini, Ramdani, \& Agum, 2021). Through Canvas teachers can share and transfer their knowledge to the students, 
while students can also join online discussion that encourage them to shape their collaborative and cooperative skills in completing the task given by the teacher. Therefore, Canvas is an ideal LMS that can contribute in making teaching and learning process more interactive, especially in online learning setting.

Additionally, Canvas is also considered as a helpful LMS, since it helps the students to gain better understanding about the learning materials (Edmunds, Thorpe, \& Conole, 2012; Fauzi et al, 2020). Moreover, Fauzi et al (2020) in their study also witness that Canvas is effective and it has large effect on students' learning outcomes in online learning. It is confirmed by the result of this study, by which the students mentioned that besides their understanding of the course materials, their language skills and also vocabulary mastery are also improved after they use Canvas for online learning. It means that Canvas is effective to enhance the students' learning outcomes in general.

They also claimed that they feel interested and motivated in joining the instruction, and it is also an important factor to support the success of learning (Mantiri, 2015; Utvaer and Haugan, 2016). In addition, Al-Khoeri, Nuraini, Ramdani, \& Agum (2021) also find in their study that students felt comfortable, surprised, and engaged even though there are some obstacles they have experienced in using Canvas for online learning. Canvas gives them new learning experience that can attract their attention and motivate them to improve their learning.

To sum up, the findings of this study demonstrate the correlation between students perceptions related to the use of Canvas for interactive online learning. In this regard, TAM asserts that Perceive Usefulness (PU) will be influenced by (perceive Ease of Use (PEOU), by which the users perceive the technology as a useful one, when they find that it is easy to use (Davis, 1989). It is proven in this study that students perceived that Canvas is an easy LMS to use for online learning, they also considered that it is useful to support the interactive online learning. Therefore, the teachers are invited to consider Canvas as a valuable LMS to use, that can promote the more interactive, effective, and interesting online learning.

\section{Conclusion and Suggestion}

The findings of this study revealed that the majority of the participants had a favourable opinion of using Canvas to create an interactive learning environment. According to the results of the questionnaire, students agreed that utilizing Canvas 
was useful, beneficial, and effective in assisting them in learning English at any time and from any location. They also believe that using Canvas will help them enhance not only their reading comprehension but also their writing and speaking skills. Furthermore, the data shows that students have a favourable attitude regarding the utilization of mobile learning through Canvas.

On the other side, there were certain disadvantages to utilizing Canvas, such as issues with internet access and network connectivity. Several students subsequently indicated that they had difficulty in operating the mobile version of Canvas application, and they were having trouble finding certain feature of this LMS.

Nonetheless, while Canvas had some limitations, the benefits it provided to students' learning activities and performances outweighed the disadvantages. This advantage could be extended to their learning outcomes, particularly in interactive learning environments. Finally, there was a favourable opinion of using Canvas for interactive learning.

\section{References}

Adams, W.C. (2015). Conducting Semi-Structured Interviews. In: Wholey, J.S., Harty, H.P. and Newcomer, K.E., Eds., Handbook of Practical Program Evaluation, Jossey-Bass, San Francisco, 492-505.

Adzharuddin, N. A., \& Ling, L. H. (2013). Learning management system (LMS) among university students: Does it work. International Journal of e-Education, eBusiness, e-Management and e-Learning, 3(3), 248-252.

Aldiab, A., Chowdhury, H., Kootsookos, A., Alam, F., \& Allhibi, H. (2019). Utilization of Learning Management Systems (LMSs) in higher education system: A case review for Saudi Arabia. Energy Procedia, 160, 731-737.

Al Khoeri, A. F., Nuraini, W., Ramdani, R., \& Agum, S. (2021, March). The implementation of Canvas to enhance english teaching and learning. In International Conference on Education of Suryakancana (IConnects Proceedings).

Andrei, E. (2017). Technology in teaching English language learners: The case of three middle school teachers. TESOL Journal, 8(2), 409-431.

Basal, A. (2016). Extending the functionality of LMS for English language teaching. In Conference proceedings. ICT for language learning (p. 142). libreriauniversitaria. it Edizioni.

Binyamin, S. S., Rutter, M. J., \& Smith, S. (2019). Extending the Technology Acceptance Model to Understand Students' use of Learning Management 
Systems in Saudi Higher Education. International Journal of Emerging Technologies in Learning, $14(3), 4-21$.

Braun, V., \& Clarke, V. (2006). Using thematic analysis in psychology. Qualitative research in psychology, 3(2), 77-101.

Carbonilla Gorra, V. \& Bhati, S. S. (2016). Students' perception on use of technology in the classroom at higher education institutions in Philippines. Asian Journal of Education and e-Learning, 4 (3), 92-103.

Cavus, N. (2009). The evaluation of Learning Management System using an Artificial Intelligence Fuzzy Logic Algorithm. Advances in Engineering Software, 41 (2), 248-254.

Davis, F. D. (1989). Perceived usefulness, perceived ease of use, and user acceptance of information technology. MIS quarterly, 319-340.

Edmunds, R., Thorpe, M., \& Conole, G. (2012). Student attitudes towards and use of ICT in course study, work and social activity: A technology acceptance model approach. British journal of educational technology, 43(1), 71-84.

Efron, R. (1969). What is perception?. In Proceedings of the Boston Colloquium for the Philosophy of Science 1966/1968 (pp. 137-173). Springer, Dordrecht.

Ekinci, E., \& Ekinci, M. (2017). Perceptions of EFL learners about using mobile applications for English language learning: A case study. International Journal of Language Academy, 5(5), 175-193.

Ertmer, P. A., \& Ottenbreit-Leftwich, A. (2010). Teacher technology change: How knowledge, confidence, beliefs, and culture intersect. Journal of Research on Technology in Education, 42, 255-284. doi:10.1080/15391523.2010.10782551.

Fandiño, F. G. E., Muñoz, L. D., \& Velandia, A. J. S. (2019). Motivation and E-Learning English as a foreign language: A qualitative study. Heliyon, 5(9), e02394. https://doi.org/10.1016/j.heliyon.2019.e02394.

Fathema, N., Shannon, D., \& Ross, M. (2015). Expanding the Technology Acceptance Model (TAM) to examine faculty use of Learning Management Systems (LMSs) in higher education institutions. Journal of Online Learning \& Teaching, 11 (2). 210-232.

Fatimah, A. S., \& Santiana, S. (2017). Teaching in 21 st century: Students-teachers' perceptions of technology use in the classroom. Script Journal: Journal of Linguistic and English Teaching, 2(2), 125.

Fauzi, M., Murdiono, M., Anindiati, I., Lu'lu In Nada, A., Rohmanul Khakim, R., \& Mauludiyah, L. (2020). Developing Arabic language instructional content in Canvas LMS for the era and post Covid-19 pandemic. Izdihar: Journal of Arabic Language Teaching, Linguistics, and Literature, 3(3), 161-180. 
Jusuf, H., Nurdin Ibrahim, \& Atwi Suparman. (2021). Development of Virtual Learning Environment Using Canvas To Facilitate Online Learning. JTP - Jurnal Teknologi Pendidikan, 23(2), 153-167. https://doi.org/10.21009/jtp.v23i2.22240

Khoa, B. T., Ha, N. M., Nguyen, T. V. H., \& Bich, N. H. (2020). Lecturers' adoption to use the online Learning Management System (LMS): Empirical evidence from TAM2 model for Vietnam. ECONOMICS AND BUSINESS ADMINISTRATION, 10(1), 3-17.

Mantiri, O. (2015). Key to Language learning success. Journal of Arts and Humanities, 4 (1), 14-18. https://doi.org/10.18533/journal.v4i01.629.

Nomass, B. B. (2013). The impact of using technology in teaching English as a second language. English language and literature studies, 3(1), 111.

Pujasari, R.S., \& Ruslan. (2021). Utilizing Canvas in technology enhanced language learning classroom: A case study. An English article. Journal of English Literacy and Education, 8(1), 42- 54

Utvaer, B. K. S., \& Haugan, G. (2016). The academic motivation scale: dimensionality, reliability, and construct validity among vocational students. Nordic Journal of Vocational Education and Training, 6(2), 17-45.

Yin, Robert K. (2003). Case Study Research: Design and Methods, Third Edition, Applied Social Research Methods, Volume 5, Sage Publications. 